\title{
EDUCAÇÃO AMBIENTAL: COMPREENDER O CONTEXTO SOCIOAMBIENTAL
}

\author{
Mário José Puhl ${ }^{1}$
}

Resumo: O artigo apresenta uma perspectiva teórica que fundamenta, contribui na realização dos princípios, das diretrizes e dos objetivos estabelecidos e das políticas afetas à Educação Ambiental. Reflete esta práxis educativa na condição de ação interpretativa e via compreensiva das relações ambientais, realizada pela linguagem, configurando um ensaio teórico, a partir da análise documental e pesquisa bibliográfica. Nesta perspectiva a Educação Ambiental, o sujeito e os sentidos do meio ambiente se constituem mutuamente, numa relação dialógica da interpretação, compreensão e construção de mundo comum. Ela ocorre em um ambiente socioambiental e histórico realizado pelos humanos, na sua condição humana finita.

Palavras-chave: Ambiente; Compreensão; Educação Ambiental; Relação Dialógica.

\footnotetext{
1 Doutorando do Programa de Pós-Graduação em Educação nas Ciências da Universidade Regional do Noroeste do Estado do Rio Grande do Sul. Professor na FEMA. E-mail: mariopuhl@yahoo.com.br
} 


\section{Introdução}

As preocupações objetivas em relação ao ambiente natural, ou seja, aos níveis e formas de contaminação dos bens ambientais (água, terra, ar, florestas), à degradação dos bens ambientais e de sua qualidade, à tomada de consciência dos limites dos recursos naturais disponíveis para utilização humana, são recentes. Situam-se no período pós a Segunda Guerra Mundial, bem como os movimentos pacifistas seguidos ao período do conflito bélico mundial, no contexto da Guerra Fria. É o lançamento das bombas atômicas jogadas sobre a população civil das cidades japonesas de Hiroshima e Nagasaki, pelos EUA, que torna pública a possibilidade do uso da razão instrumental contra a humanidade, a qual poderia ser destruída pelos humanos e a totalidade do Planeta.

Em termos filosóficos, a Escola de Frankfurt ${ }^{2}$, contribui para o surgimento da preocupação pública dos problemas ambientais, pela Teoria Crítica. Teoria que apresenta uma análise da razão instrumental e de sua contribuição para a degradação ambiental, na medida em que ela defende o uso das ciências e das técnicas para dominar e controlar a natureza, os indivíduos e a sociedade. A teoria crítica servirá, posteriormente, de referencial teórico e metodológico para as análises das situações socioambientais e também como referencial para a realização da Educação Ambiental.

Posteriormente, na década de 1960 situa-se a obra de Rachel Carson, Primavera Silenciosa, a qual levanta os problemas ambientais e de saúde pública, do desaparecimento de espécies, decorrentes do uso de venenos agrícolas, de pesticidas, (os biocidas). É uma obra clássica do ambientalismo contemporâneo.

É a partir da década de setenta do século XX que é trabalhada de forma mais intensa a consciência ambiental, em razão dos documentos produzidos em níveis mundiais, pela ONU, a crise energética do petróleo, desencadeada em 1973, a Guerra Fria, a os dados da situação ambiental do planeta produzidos por órgãos intergovernamentais e pela ONU.

A crise ambiental atual é um sintoma da crise civilizatória ocidental, visto que se considera que a origem desta crise está na ação humana. Várias são as abordagens desta crise, suas causas e quais seriam as possíveis perspectivas de saída da mesma, tais como apontam Leff $(2010 ; 2012)$, Dias (2013), Saavedra (2014), Hathawway e Boff (2012), Welzer (2010) e Morin (2013) e Giddens (2010), Veiga (2007), dentre outros estudiosos da temática socioambiental e sua

\footnotetext{
2 A Escola de Frankfurt foi criada em 03 de fevereiro de 1923, na cidade de Frankfurt, Alemanha, e sediada na Universidade de Frankfurt. Inicialmente era denominado de Instituto de Pesquisas Sociais, este Instituto surgiu com o propósito de fomentar discussões teóricas relativas ao marxismo, atualizando este referencial filosófico. Somente em 1950 é que o Instituto passa a ser chamado de Escola de Frankfurt em razão do regresso da revista que era editada pela instituição à Alemanha visto que esta havia sido transferida para a França, no ano de 1933, conforme relata Assoun (1991). Filósofos e outros intelectuais associaram-se à Escola de Frankfurt balizam suas produções em torno dos princípios da Teoria Crítica, dentre os quais destaca-se Horkheimer, Adorno, Marcuse, Benjamin, Fromm e Habermas.
}

revista brasileira educação ambiental 
interface com a ação humana. Dentre as tantas formas de enfrentamento do quadro da crise socioambiental está a Educação Ambiental.

O texto está organizado em duas partes, sendo que na primeira aborda a origem, marcos e referências da Educação Ambiental e na segunda parte busca estabelecer um fundamento teórico, não metafísico, para a Educação Ambiental, a partir do referencial filosófico interpretativo, pensado a partir de Heidegger, Habermas e Vattimo, mediado pela linguagem.

\section{Situando a Educação Ambiental}

Busca-se, previamente, citar os diversos eventos nacionais $e$ internacionais ocorridos nas últimas décadas que contribuíram para a efetivação da Educação Ambiental.

A preocupação, de forma objetiva e direta, com a Educação Ambiental resulta de um evento realizado no Reino Unido, no ano de 1965, promovido pela Universidade de Keele, denominado de Conferência de Keele. Neste evento houve a concordância que a dimensão ambiental deveria ser abordada na educação escolar formal, conforme aponta Dias (2013).

$\mathrm{Na}$ Conferência das Nações Unidas sobre o Ambiente Humano, realizada em Estocolmo no ano de 1972, ressaltou-se a importância da inter-relação entre educação e ambiente, colocando a temática ambiental em patamar internacional e oficial na Organização das Nações Unidas - ONU. Decorrente desta articulação e importância dada a Organização para a Educação, Ciência e Cultura (UNESCO) e o Programa das Nações Unidas para o Meio Ambiente (PNUMA), elaboraram o Programa Internacional de Educação Ambiental (PIEA).

Em face deste programa educacional protagonizado pela UNESCO, PNUMA e PIEA, a ONU promoveu, no ano de 1975, o I Seminário Internacional de Educação Ambiental, na cidade Belgrado, luguslávia, cujo encontro elaborou a Carta de Belgrado. Para Dias (2013) este evento enfatizou que a Educação Ambiental se constitui em um processo amplo, formal ou não, o qual abarca as dimensões culturais e sociais, políticas e econômicas, capaz de produzir novas habilidades, princípios e práticas compatíveis com a sustentabilidade da vida, em todas as suas formas e manifestações, no planeta. Preconizou também a necessidade da superação dos problemas sociais e econômicos articulados com a temática e problemática ambiental.

Após este seminário internacional, outros eventos ocorreram. Alguns destes com abrangência mais restrita - regional, nacional ou local - outros com alcance mundial. Em termos sul-americanos, foi realizado o Taller Subregional de Educación Ambiental para Educación Secundaria, na cidade Chosica, no Peru, em 1976. Este encontro demarcou sua concepção da relação direta entre o social e o natural e a necessidade da transformação das sociedades em suas estruturas básicas para a resolução dos problemas socioambientais. Afirmou princípios metodológicos da Educação Ambiental, como: participativa, 
permanente, interdisciplinar, construída a partir do cotidiano das pessoas envolvidas. Definiu a Educação Ambiental como:

la acción educativa permanente por la cual la comunidad educativa tiende a la toma de consciencia de su realidad global, Del tipo de relaciones que los hombres establecen entre sí y la natureleza, de los problemas derivados de dichas relaciones y sus causas profundas. Ella desarrolla, mediante una práctica que vincula al educando con la comunidad, valores y actitudes que poromoven un comportamiento dirigido hacia la transformación superadora de esa realidad, tanto em sus aspectos naturales como sociales, desarrollando em el educando las habilidades y aptitudes necesarias para dicha transformación (UNESCO, 1976, p. 10).

Conforme evidenciado por Dias (2013), a crescente preocupação com a temática ambiental, por parte de organizações internacionais, conduziu à realização da Conferência Intergovernamental sobre Educação Ambiental, cujo evento se constitui uma referência à temática da Educação Ambiental, em termos mundiais. Esta conferência foi realizada em outubro de 1997, em Tbilisi, na Geórgia, a qual estabeleceu os princípios, os objetivos, as características, as recomendações da Educação Ambiental, em termos nacionais e no plano internacional. Uma educação que deveria potencializar a participação dos indivíduos e as instituições públicas para o enfrentamento destes problemas. Apontou para a Educação Ambiental como o meio educativo capaz de fazer compreender a interface entre as dimensões ambiental e social e para superar a visão meramente conservacionista da prática educativa na área ambiental.

O Seminário Educação Ambiental para a América Latina e o Seminário Latino-Americano de Educação Ambiental aconteceram na Costa Rica em 1979 e na Argentina em 1988, respectivamente. Estes dois seminários destacaram as contribuições fundamentais das mulheres na promoção do desenvolvimento local e das culturas ecológicas e ao mesmo tempo sublinharam a necessidade da preservação do patrimônio histórico-cultural como parte integrante do ambiente no qual se vive.

No ano de 1987 ocorreu, em Moscou, o Congresso Internacional de Educação e Formação Ambientais, o qual avaliou as ações realizadas e ratificou as diretrizes de Tbilisi. Segundo, apontou para a necessidade da formação técnica a qual seria capaz de realizar ações sustentáveis e destacou a importância da organização de redes de informação e comunicação entre os profissionais da Educação Ambiental.

Na sequência ocorreu a Jornada Internacional de Educação Ambiental, realizada no Rio de Janeiro, em 1992, simultaneamente à Conferência Rio-92. Nesta jornada foi produzido e divulgado o Tratado de Educação Ambiental para Sociedades Sustentáveis e Responsabilidade Global, estabelecendo um conjunto de compromissos coletivos para a sociedade civil em termos planetários para com o meio ambiente.

revista brasileira educação ambiental 
Cinco anos mais tarde, em Thessaloniki ocorreu a Conferência Meio Ambiente e Sociedade: Educação e Consciência Pública para a Sustentabilidade. Este evento considerou como prioritária a formação de professores para a Educação Ambiental, a produção de materiais didáticos e a realização de encontros de formação e de troca de experiências educativas entre educadores ambientais em nível local.

Rocha (2002) observa que tanto em Moscou quanto em Thessaloniki as ratificações dos princípios de Tbilisi e os constantes apelos à mudança de comportamentos humanos em relação ao ambiente natural, são permeados pelos questionamentos sobre os rumos da humanidade. Da mesma maneira questiona as razões que fazem com que os projetos educacionais na área ambiental, as tarefas sugeridas a serem realizadas nos países signatários dos eventos e seus documentos, não conseguem alterar os níveis de degradação ambiental e os comportamentos humanos ante este problema. Dito de outra maneira, os resultados esperados não estão ocorrendo. Por outro lado, os encontros de Tbilisi e de Moscou, apontaram para a necessidade de uma pedagogia tecnicista capaz de dar conta de alterar o quadro de degradação ambiental e de suas consequências - conforme pode ser visto nas recomendações de número dois, onze e quatorze, do documento de Tbilisi. A solução apontada para a resolução dos problemas ambientais deveria ser técnica e a Educação Ambiental com um viés pragmático.

Em termos de fundamentos da práxis educativa ambiental Gohn (2011) identifica três eixos teóricos presentes nos documentos emitidos pelos eventos que tratam do tema da Educação Ambiental: o liberal, o revolucionário e o democrático radical. Cada qual enfatiza, prioriza e direciona suas ações de forma distinta. O primeiro eixo sublinha as ações individuais, em sua capacidade de realizar suas escolhas livres e racionais e na independência da sociedade civil em relação ao Estado, privilegiando da esfera privada. $O$ eixo revolucionário aposta no coletivo, na organização popular e social com vistas à ruptura da estrutura da sociedade vigente. A perspectiva democrática aposta no fortalecimento da democracia, da democracia substantiva e no protagonismo dos sujeitos e das organizações.

No Brasil, a Educação Ambiental antecede-se à sua institucionalização formal por parte do Estado. De acordo com Dias (2000) esta temática emerge através de artigos de autores nacionais e de um estruturado movimento conservacionista dos recursos naturais; e que no ano de 1970 foi fundada a Associação Gaúcha de Proteção ao Ambiente natural, a qual se constitui na precursora dos movimentos ambientalistas no país.

De forma institucional e por parte do poder público, o debate ambiental se instaurou no país durante a vigência da ditadura civil-militar (1964/1985), na década de 1970, por pressões internacionais advindas dos organismos ligados à temática ambiental e de organizações brasileiras. Naquele período histórico a preocupação com temática ambiental era vista como um obstáculo à consolidação do projeto desenvolvimentista de tornar o país em uma potência 
econômica, bélica e energética, sob os auspícios da ideologia modernizanteconservadora, observa Dias (2000; 2013).

Ainda conforme este mesmo autor, até a promulgação da Constituição Federal de 1988 a política ambiental brasileira ocorria de forma esparsa, fragmentada e sem uma caracterização objetiva. A lei federal $n . \stackrel{6}{6.938}$, de 31 de agosto de 1981, instituiu a Política Nacional do Meio Ambiente a qual estabelece algumas exigências técnicas a serem cumpridas para a instalação e funcionamento de empreendimentos econômicos. Esta lei estabelece exigências, critérios técnicos para a as atividades econômicas com vistas a conciliar a preservação ambiental e o desenvolvimento econômico. Ou dito de outra maneira, a preocupação com a conservação ambiental não mais era entendida, oficialmente, como sinônimo de atrapalho ao crescimento econômico do país, de um lado, e, por outro lado, o Estado busca regular as atividades econômicas a serem desenvolvidas no Brasil.

A dinâmica de institucionalização da Educação Ambiental no Brasil teve início no ano de 1973 com a criação da Secretaria Especial do Meio Ambiente SEMA. Foi o primeiro organismo oficial, de caráter nacional, orientado para a gestão integrada do meio ambiente, do controle da poluição, da capacitação de pessoas para a sensibilização da sociedade sobre as questões ambientais e que deu início aos projetos de Educação Ambiental voltados para a inserção da temática ambiental nos currículos escolares (Brasil, 2005). A extinta SEMA também realizou cursos de ecologia para educadores ambientais. Em conjunto com a Capes, CNPq, UnB e Pnuma formatou o primeiro curso de especialização em Educação Ambiental do país, o qual aconteceu nos anos de 1986 a 1990, escreve Arruda (2001).

A formalização legal da Educação Ambiental no país ocorreu com a promulgação da Carta Magna de 1988, no artigo 225, inciso VI. Em que pese que a centralidade da Educação Ambiental expressa neste artigo constitucional focar-se na preservação do meio ambiente, os debates e ações relativas ao ambiente avançaram no cenário nacional, seja de por ações do poder público ou através das mobilizações das organizações sociais ligadas à temática socioambiental.

O Programa Nacional de Educação Ambiental - ProNEA foi criado em 1994. Este programa prevê sete linhas básicas de atuação: Educação Ambiental em todos os níveis de ensino formal; educação no processo da gestão ambiental; realização de campanhas específicas junto aos usuários e exploradores de recursos naturais; integração entre os meios de comunicação social para a formação da consciência ambiental; articulação e integração das comunidades com vistas à sustentabilidade; articulação interinstitucional para promover a Educação Ambiental; criar uma rede de centros especializados em Educação Ambiental, integrando universidades, escolas profissionalizantes, institutos de pesquisa em todos os Estados da federação.

Os Parâmetros Curriculares Nacionais (PCN), elaborados com base na LDBEN e vigentes desde 1997, estabeleceram vários temas transversais em 
razão da relevância social, urgência e universalidade. O tema do meio ambiente é definido como assunto interdisciplinar. Não é definido, portanto, como uma matéria específica dos currículos escolares. Nesta compreensão apresenta um conjunto de demandas para a formação dos futuros docentes para todas as áreas do conhecimento e para todos os níveis de ensino. Temática que não constitui objeto de preocupação neste texto, mas que enseja estudos para verificar como ocorre este preparo e as possíveis referências teóricas desta formação de professores.

A I Conferência Nacional de Educação Ambiental, ocorrida em 1997, produziu o documento denominado Declaração de Brasília no qual constam as temáticas e as recomendações para a Educação Ambiental brasileira, que de acordo com Arruda (2001) estão organizadas em eixos: Educação Ambiental e as vertentes do desenvolvimento sustentável; Educação Ambiental formal; Educação Ambiental no processo de gestão ambiental; Educação Ambiental e políticas públicas; Educação Ambiental, ética e formação da cidadania.

Em termos estritamente legais a Política Nacional de Educação Ambiental foi instituída pela Lei Federal n.ำ 9.795/1999, a qual estabelece os princípios básicos e os objetivos fundamentais da Educação Ambiental. Este diploma legal vincula os processos formais de educação a práticas sociais educativas e estabelece a necessidade da transversalidade da temática ambiental nos currículos escolares, em todos os níveis de ensino.

Em 2001 foi criado o Sistema Brasileiro de Informação em Educação Ambiental e Práticas Sustentáveis - SIBEA. Este sistema tem por finalidades organizar, sistematizar e difundir conhecimentos elaborados em Educação Ambiental e articular ações governamentais das diversas esferas administrativas do país.

Este percurso histórico relativo è Educação Ambiental, no contexto brasileiro e mundial, evidencia diversas preocupações com o tema, seja de ordem dos seus pressupostos teóricos, referenciais, formas de execução e as distintas maneiras de perceber o contexto da problemática ambiental e suas possíveis soluções. Assume-se neste trabalho, que os problemas socioambientais, exceto os fenômenos naturais, catastróficos ou não, (tais como vulcões, terremotos, raios, tsunamis, ventos), decorrem da ação humana, conforme dados divulgados pela ONU e seus organismos. Ou seja, resultam do paradigma civilizatório adotado pela humanidade, no qual alguns países possuem uma responsabilidade maior pela origem dos problemas. Da mesma maneira, grupos humanos possuem uma maior responsabilidade pelos problemas socioambientais, dado seu padrão de consumo e formas de produção de riquezas. Neste sentido, esta problemática é um desafio de ordem política e deverá ser enfrentada nesta perspectiva - sem desconsiderar as relações assimétricas entre os indivíduos, os países, blocos econômicos e organizações privadas, tal como evidenciam Saavedra (2014), Giddens (2010), Welzer (2010), Hathaway e Boff (2012). O enfrentamento público deste dilema, além de político, também enseja um processo educativo, o qual será apresentado a seguir. 


\section{Educação Ambiental: via compreensiva de relação socioambiental}

Diversas são as práticas sugeridas e adotadas para desenvolver ações de Educação Ambiental, sejam elas no ensino formal (escolar) ou não. Estas práticas podem ser categorizadas em duas grandes áreas: uma delas é que trabalha para remediar os efeitos já existentes, ou seja, buscar corrigir o estrago produzido ou recuperar áreas degradadas. Aposta muito na formação de valores humanos, a formação da consciência ambiental e da aquisição de conhecimentos técnicos para resolver o problema. Diferente desta perspectiva está situada a proposição da prudência na ação humana, teoria oriunda da filosofia de Aristóteles (2009) ou do princípio da responsabilidade, pensado por Jonas (2011), formação ética defendida por Grün (2012), dentre outras perspectivas. Estas diferentes perspectivas apontam para formas pedagógicas diversas ou maneiras práticas de realizar este processo educativo.

Diferente da perspectiva explicativa busca-se, neste espaço, tematizar a práxis social da Educação Ambiental na condição de ação interpretativa e via compreensiva de acesso ao meio ambiente. Na tradição filosófica da perspectiva compreensiva está presente a hermenêutica e que também se contrapõe ao método explicativo o qual orienta as investigações das ciências naturais. Hermenêutica, entendida por Flickinger (1998, p. 368) como "doutrina de compreensão, ou seja, de uma postura que busca sentido através da interpretação dos fatos, não se contentando com sua mera explicação".

Acolher a assumir este referencial, este fundamento teórico na Educação Ambiental requer o deslocamento de sua proposição meramente tecnicista. Problematizar sua aposta nas ciências naturais, para depreender seus possíveis sentidos e alargar o conceito de interpretação no espaço da Educação Ambiental.

Interpretar é uma categoria fundamental e central na filosofia e nas ciências sociais que pautam seu referencial teórico na hermenêutica. É uma de compreender e explicar os conhecimentos elaborados historicamente, nos mais distintos contextos sociais e ambientais.

O pensamento das ciências nos procedimentos objetificadores, calculáveis (matemáticos), do método experimental, estabelece que a verdade deve sempre corresponder à uma determinada realidade, a um determinado fato ou objeto. A verdade deve corresponder com o real e esta correspondência impõe-se como critério de validade do conhecimento e das ciências em todas as áreas do conhecimento. No plano empírico, esta sintonia foi estabelecida na correlação entre um dado, um fato ou uma lei geral que a explica. No plano filosófico se expressa na equivalência entre o conceito (ou imagem) e o real.

A tese da verdade como correspondência com o real foi criticada, fato que inicia com Nietzsche (2009) e seguido por Heidegger (2012) e com os trabalhos de hermeneutas como Gadamer (2004; 2011), Vattimo (1992), Habermas (2002), dentre outros. Estes autores estabeleceram uma crítica ao paradigma racionalista e idealista, isto é, metafísico. Colocam em questão o fundamento epistemológico metafísico do credo no pensamento (da razão) como apreensão

revista brasileira educação ambiental 
de algo, de um real verdadeiro e certo e ao mesmo tempo estabeleceram outro referencial para o produzir do conhecimento, que é a hermenêutica, mediado pela linguagem.

Geertz (2013) caracteriza esta mudança conceitual, a partir da hermenêutica, de giro cultural e de giro interpretativo. Entende o antropólogo, que a vida social é constituída e organizada simbolicamente, onde o conhecimento é produzido como interpretação a partir do que este autor chama de construções ou analogias explicativas.

Radicalizar a ideia de compreensão como interpretação é o que realiza a hermenêutica, diferindo da tradição metafísica. Para Vattimo (1992), a hermenêutica constitui-se em um método de produção do conhecimento, embasada na argumentação narrativa e interpretativa do fato, do mundo, da natureza.

Neste fundamento teórico, a linguagem humana constitui-se como o meio mais adequado da experiência humana do mundo. A subjetividade não se constitui em consciência isolada na busca de desvendar os sentidos dados, estabelecidos, mas ela própria fala e é falada pela e na linguagem, constituindo o sujeito no mundo simbólico. Gadamer sustenta a tese de que a linguagem

é o meio universal em que se realiza a compreensão mesma. A forma de realização da compreensão é a interpretação. Todo compreender é interpretar e toda interpretação se desenvolve em meio a uma linguagem que pretende deixar falar o objeto e ao mesmo tempo a linguagem própria de seu intérprete (2004, p. 467).

Pela linguagem se realiza a análise e a interpretação, o olhar e o compreender. E nela que se dá a relação da interpretação e a compreensão, a relação entre o eu e a natureza. Nas palavras de Gadamer (2004, p. 567): "a linguagem é onde se encontram o eu e o mundo".

A hermenêutica se apresenta como uma abordagem fundamental, distinta da visão metafísica, para fundamentar a realização da Educação Ambiental. Cumpre um papel importante na virada paradigmática que supera a filosofia da consciência. No entender de Bombassaro (1992), questiona as próprias condições de possibilidade dessa consciência autocentrada. Situa a condição humana no mundo, na história e na linguagem e não como um sujeito senhor de si, separado da natureza ou acima dela. Os humanos estão inseridos no círculo hermenêutico e o próprio movimento de compreensão é englobante e universal, abrangendo a experiência humana do mundo (GADAMER, 2004; 2011).

A Educação Ambiental na perspectiva hermenêutica situa esta como uma práxis na qual o sujeito e os sentidos do ambiente se constituem mutuamente na relação dialógica da interpretação e compreensão, mediada na linguagem. $O$ sujeito e intérprete estão no mundo produzindo sentidos e conhecimento a partir Revbea, São Paulo, V. 11, № 4: 184-196, 2016. 
de seu horizonte histórico e do legado trazido pela tradição na qual ambos se situam e com a qual dialogam. É uma perspectiva que recusa a dualidade ou o antagonismo entre pensamento e ação, entre o humano e a natureza. O humano sempre está em um ambiente, na natureza e esta somente existe pelo significado humano atribuído a ela, pela linguagem. Os sentidos produzidos na linguagem são as condições, referências da ação humana no mundo. A ação acontece com base na compreensão produzida em um universo de múltiplas interpretações, leituras, pois ela está implicada no próprio ato interpretativo. Não há ação sobre ou decorrente de (relação de causa e efeito), mas ação no espaço ambientalmente e culturalmente constituído nas relações socioambientais.

A interpretação busca evidenciar os horizontes de sentido históricoculturais que configuram, orientam as relações no ambiente natural para uma determinada sociedade ou grupo humano em um determinado tempo histórico.

Supera-se a visão de meio ambiente como um lugar isolado, intocável, inculto ou selvagem, reduzido a recursos à disposição do uso ou exploração humana ou às leis naturais universais e necessárias capazes de serem conhecidas pela razão humana. A referência hermenêutica compreende o ambiente natural como uma realidade linguística, passível de múltiplas interpretações, leituras e de possibilidades de agir. Nenhuma destas hipóteses está previamente definida, estabelecida, seja ao modo de um telos e de ordem metafísica. Cada olhar, cada interpretação evidencia novas compreensões e possibilidades de construir um mundo comum. Ao mesmo tempo em que o humano observa, ele é observado visto que faz parte da realidade observada. Interpreta e compreende na medida em que é interpretado e compreendido.

Não existe a possibilidade de que o sujeito conhecedor tome uma postura objetificador e, portanto, dominadora frente aos objetos ou à natureza. O sujeito conhecedor está sempre inserido em uma dinâmica que o ultrapassa amplamente. Ele está sempre inscrito no horizonte fornecido pela história, pela cultura e pela linguagem, e esse horizonte é, por princípio, não subjugável ou dominável (GRÜN, 2012, p. 108).

É uma educação que não se desvincula da tradição na qual está inserida e com a qual dialoga. A educação é sempre uma Educação Ambiental, pois toda ela ocorre em um determinado ambiente cultura e natural (este mais ou menos alterado pela ação humana) e em um determinado contexto histórico realizado por humanos, na sua condição finita e humana. Proposição esta que enseja que a Educação Ambiental considere os contextos locais, as singularidades culturais e ambientais, mas sem perder de vista que o meio ambiente forma um todo articulado. As ações locais têm repercussões que ultrapassam as fronteiras políticas, as delimitações históricas. Igualmente, a conservação das condições ambientais possui uma responsabilidade sincrônica, entre as gerações existentes e, diacrônica, isto é, com as gerações futuras. É o ambiente natural e

revista brasileira educação ambiental 
cultural que necessita ser preservado e é neles que acontecem a práxis educacional. Preservar o mundo que é comum a todos.

\section{Conclusões}

A Educação Ambiental fundamentada sob o prisma hermenêutico resitua a relação humana na natureza. Estabelece-se a igualdade entre as partes, sem a anulação de uma em detrimento da outra. Supera-se a relação sujeito antropocêntrico dominador (o homem, consciente e racional) e objeto (natureza, irracional e a serviço do sujeito).

Os sentidos da natureza são produzidos, na linguagem, sem verdades e métodos de aprendizagem pré-estabelecidos capazes de conduzir a leitura ou definir quais verdades deverão ser produzidas e que conduzirão as ações humanas.

O conhecimento toma a radicalidade da historicidade humana e natural, retirando-se das tradições que postulam um fundamento teleológico ou material fora da linguagem. Os saberes são construídos intersubjetivamente, onde a natureza e o humano falam e são falados. A condição humana é constituída nas relações educativas, historicamente situadas, constituidoras de um mundo onde todas as formas de vida possam se manifestar e continuar existindo. Um mundo comum à todas as formas de vida.

\section{Agradecimentos}

À Coordenação de Aperfeiçoamento de Pessoal de Nível Superior (CAPES), pelo apoio financeiro à pesquisa; à Universidade Regional do Noroeste do Estado do Rio Grande do Sul, por tornar possível o doutoramento do autor.

\section{Referências}

ARISTÓTELES. Ética a Nicômaco. 3. ed. Tradução Edson Bini. Bauru: Edipro, 2009.

ASSOUN, P-L. A escola de Frankfurt. Tradução Helena Cardoso. São Paulo: Ática, 1991.

ARRUDA, M.P. Educação e sustentabilidade: o projeto de Educação Ambiental no ensino básico do Brasil - Muda o mundo, Raimundo! Dissertação. UFRJ, Rio de Janeiro, 2001.

BOMBASSARO, L.C. As fronteiras da epistemologia: como se produz conhecimento. Petrópolis: Vozes, 1992.

BRASIL. ProNEA: Programa Nacional de Educação Ambiental. 3. ed. Brasília: Ministério do Meio Ambiente, 2005. 
BRASIL. Constituição: 1988. 18. ed. Brasília: Câmara dos Deputados, 2002. Série textos básicos, n. 27.

BRASIL. Lei no 9.795, de 27 de abril de 1999. Dispõe sobre a Educação Ambiental, institui a Política Nacional de Educação Ambiental e dá outras providencias. Disponível em: http://www.planalto.gov.br/ccivil 03/leis/l9795.htm. Acesso em: 06 out. 2014.

BRASIL. Lei no 6.938, de 31 de agosto de 1981. Dispõe sobre a Política Nacional do Meio Ambiente, seus fins e mecanismos de formulação e aplicação, e dá outras providências. Disponível em: http://www.planalto.gov.br/ccivil 03/leis/l6938.htm. Acesso em: 07 out. 2014.

CARSON, R. Primavera silenciosa. Tradução Claudia Sant'Anna Martins. São Paulo: Gaia, 2010.

DIAS, G.F. Educação Ambiental: princípios e práticas. 9. ed. revista e ampliada, 5. reimp. São Paulo: Gaia, 2013.

DIAS, G. F. Fundamentos de Educação Ambiental. Brasília: Universa, 2000.

FLICKINGER, H-G. Sociedade, educação e meio ambiente. In: MARCON, Telmo. (Org.). Educação e universidade: práxis e emancipação. Passo Fundo: UPF, 1998. p. 365-384.

GADAMER, H-G. Verdade e método I: traços fundamentais de uma hermenêutica filosófica. 6. ed. Tradução Flávio Paulo Meurer. Petrópolis: Vozes, 2004. Coleção pensamento humano.

GADAMER, H-G. Verdade e método II: complementos e índice. 6. ed. Tradução Enio Paulo Giachini. Petrópolis: Vozes, 2011. Coleção pensamento humano.

GEERTZ, C. O saber local: novos ensaios em antropologia interpretativa. Petrópolis: Vozes, 2013.

GIDDENS, A. A política da mudança climática. Tradução Vera Ribeiro. Rio de Janiero: Zahar, 2010.

GOHN, M.G. Conselhos gestores e participação sociopolítica. São Paulo: Cortez, 2011. Coleção Questões da Nossa Época, v. 32.

GRÜN, M. Ética e Educação Ambiental: a conexão necessária. 14. ed. Campinas: Papirus, 2012. Coleção Magistério: formação e trabalho pedagógico.

HABERMAS, J. Pensamento pós-metafísico: estudos filosóficos. 2. ed. Rio de Janeiro: Tempo Brasileiro, 2002. Coleção Tempo Universitário.

HATHAWAY, M; BOFF, L. O tao da libertação: explorando a ecologia da transformação. Tradução Alex Guilherme. Petrópolis: Vozes, 2012.

HEIDEGGER, M. Ser e Tempo. 7. ed. Tradução revisada e apresentada de Márcia Sá Cavalcante Schuback. Petrópolis: Vozes; Bragança Paulista: São Francisco, 2012. Coleção pensamento humano. 
JONAS, H. O princípio responsabilidade: ensaio de uma ética para a civilização tecnológica. 1. reimp. Tradução Marijane Lisboa; Luiz Barros Montez. Rio de Janeiro: Contraponto, 2011.

LEFF, E. Saber ambiental: sustentabilidade, racionalidade, complexidade, poder. 9. ed. Tradução Lúcia Mathilde Endlic Orth. Petrópolis: Vozes, 2012. Coleção Educação Ambiental.

LEFF, E. Epistemologia ambiental. 5. ed., 1. reimp. Tradução Sandra Valenzuela. São Paulo: Cortez, 2010.

MORIN, E. A via para o futuro da humanidade. Tradução Edgard de Assis Carvalho; Mariza Perassi Bosco. Rio de Janeiro: Bertrand Brasil, 2013.

NIETZSCHE, F. Além do bem e do mal: prelúdio de uma filosofia do futuro. Tradução Mario Ferreira dos Santos. Petrópolis: Vozes, 2009. Coleção textos filosóficos.

SAAVEDRA, F.E. História do debate ambiental na política mundial: 19451992. Tradução Daniel Rubens Cenci. Ijui: Unijui, 2014.

UNESCO. Taller subregional de educación ambiental para educación secundaria. Chosica, 1976.

VATTIMO, G. A sociedade transparente. Lisboa: Relógio D’água, 1992. Coleção Antropos.

VEIGA, J.E. A emergência socioambiental. 2. ed. revista. São Paulo: Senac São Paulo, 2007.

WELZER, $\mathrm{H}$. Guerras climáticas: por que mataremos e seremos mortos no século XXI. Tradução William Lagos. São Paulo: Geração Editorial, 2010. 